\title{
Silagem de Capim-Elefante (Pennisetum purpureum, Schum) com e sem Acipin, Associada a Duas Fontes Protéicas na Alimentação de Bovinos em Confinamento
}

\author{
Hernan Maldonado ${ }^{1}$, José Fernando Coelho da Silva ${ }^{2}$, Sirlei Aparecida Maestá ${ }^{3}$, \\ Cláudio Teixeira Lombardi ${ }^{4}$
}

\begin{abstract}
RESUMO - O trabalho foi realizado com os objetivos de avaliar o consumo, a conversão alimentar e o ganho de peso de bovinos em confinamento, alimentados com silagem de capim-elefante (Penisetum purpereum, Schum.) com e sem acipin, associada ao farelo de soja e à uréia, e a digestibilidade aparente da matéria seca das silagens de capim-elefante. O confinamento experimental foi conduzido durante 167 dias, utilizando-se 28 novilhos Nelore, com média de 24 meses de idade e $310 \mathrm{~kg}$. Foram fornecidas quatro combinações de ração (T1, silagem de capim-elefante com acipin e concentrado com uréia; T2, silagem de capim-elefante com acipin e concentrado com farelo de soja; T3, silagem de capim-elefante sem acipin e concentrado com uréia; T4, silagem de capim-elefante sem acipin e concentrado com farelo de soja). O volumoso foi fornecido uma vez pela manhã e o concentrado (4 kg/animal/dia), duas vezes (pela manhã e à tarde). As ingestões médias de matéria seca em kg/animal/dia foram: T1- 6,38; T2- 6,83; T3- 6,59 e T4- 6,78. As conversões alimentares, em kg de matéria seca/kg de ganho, foram de: T1- 11,15; T2- 11,51; T3- 12,79 e T4- 10,46. Os ganhos de peso médios, em kg/animal/dia, foram de: T1- 0,552; T2- 0,593; T3- 0,515 e T4- 0,648. Consumo, conversão alimentar e ganho de peso dos animais não diferiram entre os tratamentos. Não houve diferença significativa para o coeficiente de digestibilidade da matéria seca da silagem de capim-elefante com acipin e sem acipin.
\end{abstract}

Palavras-chave: ácido lático, digestibilidade, resíduo industrial, valor nutritivo, confinamento

\section{Elephantgrass (Pennisetum purpureum, Schum) Silage with and without Acipin, Associated with two Protein Sources for Cattle Fed under Feedlot}

\begin{abstract}
The work was carried out to evaluate the voluntary intake, feed conversion and weight gain of bovines in feedlot, fed with elephantgrass silage (Penisetum purpereum, Schum.) with and without acipin associated with two protein sources, and to evaluate also the digestibility of dry matter of elephantgrass silage. The experimental feedlot was conducted during 167 days, with 28 steers, average 24 months old and initial average live weight of $310 \mathrm{~kg}$. Four rations (T1: silage with acipin and urea; T2: silage with acipin and soybean meal as protein source; T3: silage without acipin and urea and; T4: silage without acipin and soybean meal as protein source) were used. The silage was fed once a day, in the morning, and the concentrate (4 kg/animal/day) twice, in the morning and afternoon. Average daily dry matter intakes (kg) were: T1- 6.38; T2- 6.83; T3- 6.59 and T4- 6.78. Feed conversions (kg of dry matter/kg weight gain) were, T1- 11.15; T2- 11.51; T3- 12.79 and T4- 10.46. The average daily weight gains were: T1- 0.552; T20.593; T3- 0.515 and T4- 0.648. Dry matter intake, weight gain and feed: gain ratio of steers were not different among treatments. No differences were observed on dry matter digestibility coefficients of elephantgrass silages with and without acipin.
\end{abstract}

Key Words: digestibility, industrial residue, lactic acid, nutritive value, feedlot

\section{Introdução}

Os produtos de origem animal, como carne e leite, são indispensáveis à boa nutrição do homem, devendo ser produzidos com fartura e economicidade, para que possam estar disponíveis a todas as classes sociais. Para que ocorra maior disponibilidade desses produtos, é necessária adequada oferta de alimentos de boa qualidade para os animais. No Brasil, predomina o modelo extensivo de produção de bovinos. Entretanto, o uso exclusivo de pastagens não satisfaz os requerimentos dos animais para altos níveis de produtividade.

As variações sazonais na disponibilidade e no valor nutritivo das forragens ocasionam perdas de

\footnotetext{
${ }^{1}$ Professor Associado do LZNA/CCTA/UENF. Bolsista do CNPq. Avenida Alberto Lamego, 2000, Parque Califórnia, 28013-600, Campos dos Goytacazes, RJ (maldonado@uenf.br).

2 Professor Titular do LZNA/CCTA/UENF. Bolsista do CNPq (jcoelho@uenf.br).

3 Zootecnista, M.Sc, parte do trabalho de tese de Mestrado, parcialmente financiado com recursos da Fundação Estadual do Norte Fluminense (FENORTE) e doação da Purac Sintesis Ltda.

${ }^{4}$ Zootecnista, MS, Setor de Nutrição Animal do LZNA/CCTA/UENF (scezar@uenf.br).
} 
peso no período de seca. Dessa forma, o aumento de peso dos animais ocorre, basicamente, nos meses chuvosos, o que eleva a idade de abate e reduz o ganho de peso diário médio, por animal por hectare.

Inúmeros trabalhos de pesquisa têm demonstrado a influência da energia solar, temperatura e precipitação pluviométrica sobre a estacionalidade da produção forrageira em regiões tropicais, verificando-se, para as condições de Brasil central, concentração de 70 a $80 \%$, nos períodos quente e chuvoso (verão), e de 30 a 20\%, nos períodos seco e frio (inverno) (Tcacenco, 1988; Xavier et al., 1995; Tcacenco \& Botrel, 1990).

Entre as diferentes técnicas utilizadas para aumentar a velocidade de terminação dos animais, uma alternativa é manter esta forragem conservada na forma de silagem, para alimentação do rebanho no período seco do ano.

O capim-elefante (Pennisetum purpureum, Schum) destaca-se entre as gramíneas tropicais, por ser uma planta de alto potencial de produção e de boa composição bromatológica, apresentando-se como alternativa mais econômica que outras culturas anuais para produção de silagem (Tosi, 1973). Quanto ao capim-elefante, a cultivar napier utilizada para silagem, observou-se produções anuais de matéria seca, por hectare, de 20,3; 15,9 e 11,2 toneladas (Gomide et al., 1974; Pedreira et al., 1975; Pedreira \& Mattos, 1982, citados por Lavezzo et al., 1984). No entanto, uma das características das forrageiras de clima tropical é o contraste entre o valor nutritivo, influenciado pelo solo ou por peculiaridades da própria planta, e a produção por unidade de área. Várias pesquisas têm sido desenvolvidas visando buscar soluções práticas para a produção de silagens de boa qualidade a partir do capim-elefante. Uma alternativa para melhorar os padrões fermentativos e, conseqüentemente, o valor nutritivo da silagem é a utilização de aditivos (Martin, 1997). Muitos produtos têm sido comercializados como aditivos na ensilagem de milho, de sorgo ou mesmo dos capins, com diferentes propósitos, como reduzir perdas de nutrientes, estimular ou inibir fermentações ou ainda interagir no valor nutritivo da planta originalmente ensilada.

O ácido láctico tem-se apresentado como alternativa promissora na indústria alimentícia, atuando como conservante, fato atribuído à sua origem biotecnológica e suas características naturais (Den Uijl \& Van Burik, 1990). O lactato é conhecido na indústria alimentícia, por seus efeitos antimicrobiano, sinergético com antioxidantes e higroscópico, absorvendo umidade do produto, além de manter o sabor do alimento (PURAC, 1998).

Acipin é o ácido lático polimerizado residual, obtido no processo de purificação do ácido lático (aditivo alimentício) que é produzido por fermentação da sacarose (açúcar da cana). Possui aspecto líquido viscoso de coloração marrom e características físicas semelhantes ao melaço. O subproduto acipin vem sendo produzido pela empresa PURAC Sintesis Ltda., localizada no município de Campos dos Goytacazes, Estado do Rio de Janeiro. Possui teor de matéria seca $70-85 \%$ e peso específico de 1,15 a $1,30 \mathrm{~g} / \mathrm{mL}$, a $20^{\circ} \mathrm{C}$ (PURAC, 1998). Seu maior atrativo é o alto teor de ácido lático (60\%); no entanto, existem poucas informações sobre sua participação na alimentação de ruminantes.

No presente trabalho, objetivou-se avaliar o consumo, a conversão alimentar e o ganho de peso de bovinos em confinamento, alimentados com silagem de capim-elefante (Pennisetum purpureum,Schum), com e sem acipin (subproduto da produção de ácido láctico), associada ao farelo de soja e à uréia, e a digestibilidade aparente da matéria seca das silagens de capim-elefante.

\section{Material e Métodos}

O experimento foi conduzido no setor de Nutrição Animal do Laboratório de Zootecnia e Nutrição Animal da Universidade Estadual do Norte Fluminense (UENF), situado no Colégio Agrícola Antônio Sarlo, em Campos dos Goytacazes, Estado do Rio de Janeiro. O município de Campos dos Goytacazes está situado a $21^{\circ} 44^{\prime} 47^{\prime}$ ' latitude Sul e $41^{\circ} 18^{\prime} 24^{\prime \prime}$ longitude Oeste, a 12 m de altitude (Ometto, 1981). As condições climáticas do local, durante o período experimental, são apresentadas na Tabela 1 .

Foram utilizados 28 bovinos da raça Nelore, machos, castrados, com média de 24 meses de idade e $310 \mathrm{~kg}$. Antes do início do experimento, os animais foram vacinados contra febre aftosa e receberam vitaminas A, D e E, nas dosagens recomendadas pelos fabricantes (2.000.000 U.I. de vitamina A, 500.000 de vitamina D e 550 de vitamina E, para cada $50 \mathrm{~kg}$ de peso vivo).

Os animais foram mantidos em baias individuais cobertas, construídas em concreto, piso e cochos, com cordoalha de aço. A água foi fornecida em bebedouros individuais com sistemas de bóia. 
Tabela 1 - Temperaturas médias mensais, do ar (Tar), média de máximas (Tmx) e mínimas (Tmn), umidade relativa do ar (UR), radiação solar (Rad) e precipitação (Prec.), no período de julho a novembro de $1998^{1}$

Table 1 - Monthly medium temperatures, of the air (Tar), average of maximum (Tmx) and minimum (Tmn), relative humidity of the air (UR), solar radiation (Rad) and precipitation (Prec.), from July to November of 1998

\begin{tabular}{|c|c|c|c|c|c|c|}
\hline $\begin{array}{l}\text { Meses } \\
\text { Months }\end{array}$ & $\begin{array}{l}\text { Tar } \\
\left({ }^{\circ} \mathrm{C}\right)\end{array}$ & $\begin{array}{l}\text { Tmx } \\
\left({ }^{\circ} \mathrm{C}\right)\end{array}$ & $\begin{array}{l}\text { Tmn } \\
\left({ }^{\circ} \mathrm{C}\right)\end{array}$ & $\begin{array}{c}\mathrm{R} \\
(\%)\end{array}$ & $\begin{array}{c}\text { Rad } \\
\left(\mathrm{w} / \mathrm{m}^{2}\right)\end{array}$ & $\begin{array}{l}\text { Prec. } \\
(\mathrm{mm})\end{array}$ \\
\hline $\begin{array}{l}\text { Julho } \\
\text { July }\end{array}$ & 20,4 & 28,7 & 15,9 & 76,7 & 151 & 6,3 \\
\hline $\begin{array}{l}\text { Agosto } \\
\text { August }\end{array}$ & 22,1 & 27,9 & 18,4 & 80,7 & 160 & 45,9 \\
\hline $\begin{array}{l}\text { Setembro } \\
\text { September }\end{array}$ & 22,6 & 28,0 & 19,2 & 78,3 & 192 & 5,6 \\
\hline $\begin{array}{l}\text { Outubro } \\
\text { October }\end{array}$ & 22,2 & 26,6 & 19,1 & 80,7 & 160 & 106,4 \\
\hline $\begin{array}{l}\text { Novembro } \\
\text { November }\end{array}$ & 22,3 & 26,9 & 19,2 & 80,9 & 189 & - \\
\hline
\end{tabular}

Antes do início do experimento, houve um período de adaptação de 55 dias, quando os animais receberam ração comum para adaptação à dieta. As rações formuladas para atender às exigências para ganho de peso de $1 \mathrm{~kg} /$ animal/dia, segundo o NRC (1996), foram fornecidas com excesso de $10 \%$, para que houvesse sobras. O fornecimento do volumoso foi feito apenas pela manhã $(8 \mathrm{~h})$, ao passo que o concentrado foi fornecido duas vezes ao dia, $2 \mathrm{~kg}$ pela manhã (8 h), juntamente com o volumoso, e $2 \mathrm{~kg}$ à tarde (16 h). O sal mineral (mistura completa: sulfato de cobre $0,6 \%$, sulfato de ferro $2,9 \%$, sulfato de manganês $1,2 \%$, sulfato de zinco 2,9\%, selenito de sódio 1\% e cloreto de sódio 91,4\%) foi fornecido misturado à ração.

O processo de ensilagem do capim-elefante (Pennisetum purpureum, Schum) foi realizado quando este estava com, aproximadamente, 90 dias de idade e cerca de 30\% de MS. Depois de colhida e picada, a forragem foi imediatamente ensilada, totalizando $20 \mathrm{t}$ de silagem com acipin e $20 \mathrm{t}$ de silagem sem acipin. O aditivo foi colocado na dosagem de $30 \mathrm{~L}$ do material in natura/tonelada de capim (aproximadamente, $3,0 \%$ ), na forma de aspersão, conforme as etapas de compactação da silagem.

Na Tabela 2, encontra-se a composição percentual dos ingredientes do concentrado, expressa na matéria seca (MS), e na Tabela 3, as composições das silagens e do concentrado.

R. Bras. Zootec., v.33, n.6, p.2095-2103, 2004 (Supl. 2)
Tabela 2 - Composição percentual dos ingredientes do concentrado, expressa na matéria seca (MS)

Table 2 - Percent of ingredients composition of concentrate ration, in dry matter basis

\begin{tabular}{lcc}
\hline \multirow{2}{*}{$\begin{array}{l}\text { Ingredientes } \\
\text { Ingredients }\end{array}$} & \multicolumn{2}{c}{$\begin{array}{c}\text { Ração concentrada } \\
\text { Concentrate ration }\end{array}$} \\
\cline { 2 - 3 } & $\begin{array}{c}\text { Com farelo de soja } \\
\text { With soybean meal }\end{array}$ & $\begin{array}{c}\text { Com uréia } \\
\text { With urea }\end{array}$ \\
\hline $\begin{array}{l}\text { Fubá de milho } \\
\text { Ground corn grain }\end{array}$ & 62,8 & 76,1 \\
$\begin{array}{l}\text { Farelo de soja } \\
\text { Soybean meal }\end{array}$ & 34,7 & 17,9 \\
$\begin{array}{l}\text { Uréia } \\
\text { Urea }\end{array}$ & - & 3,1 \\
$\begin{array}{l}\text { Sal + mineral } \\
\text { Salt + mineral }\end{array}$ & 0,7 & 0,7 \\
$\begin{array}{l}\text { Fosfato bicálcico } \\
\text { Dicalcium phosphate }\end{array}$ & 1,8 & 1,8 \\
$\begin{array}{l}\text { Sulfato de amônia } \\
\text { Amonium sulphate } \\
\text { Total }\end{array}$ & - & 0,4 \\
\hline
\end{tabular}

Tabela 3 - Composição bromatológica dos alimentos usados no preparo das rações completas e da ração total, expressas na matéria seca

Table 3 - Chemical composition of feeds used in the ration and of the total ration, in dry matter basis

\begin{tabular}{|c|c|c|c|c|c|c|}
\hline & \multicolumn{6}{|c|}{$\begin{array}{l}\text { \% na matéria seca } \\
\% \text { in dry matter }\end{array}$} \\
\hline & $\begin{array}{l}\text { MS\% } \\
D M \%\end{array}$ & $\begin{array}{l}\mathrm{PB} \\
C P\end{array}$ & $\begin{array}{l}\text { FDN } \\
N D F\end{array}$ & $\mathrm{EE}$ & $\mathrm{Ca}$ & $\mathrm{P}$ \\
\hline $\begin{array}{l}\text { Silagem com acipin } \\
\text { Silage with acipin }\end{array}$ & 27,65 & 9,81 & 71,28 & 2,13 & 0,022 & 0,008 \\
\hline $\begin{array}{l}\text { Silagem sem acipin } \\
\text { Silage without acipin }\end{array}$ & 26,38 & 6,14 & 77,84 & 1,71 & 0,027 & 0,012 \\
\hline $\begin{array}{l}\text { Concentrado com } \\
\text { farelo de soja } \\
\text { Concentrate ration } \\
\text { with soybean }\end{array}$ & 86,98 & 23,00 & 13,70 & 3,01 & 0,52 & 0,77 \\
\hline $\begin{array}{l}\text { Concentrado com } \\
\text { uréia } \\
\text { Concentrate with urea } \\
\text { Composição das } \\
\text { rações totais }\end{array}$ & 87,72 & 24,44 & 11,90 & 3,43 & 0,52 & 0,69 \\
\hline $\begin{array}{l}\text { Ração } 1 \\
\text { Ration } 1\end{array}$ & 86,98 & 23,00 & 13,70 & 3,01 & 0,52 & 0,77 \\
\hline $\begin{array}{l}\text { Ração } 2 \\
\text { Ration } 2\end{array}$ & 87,72 & 24,44 & 11,90 & 3,43 & 0,52 & 0,69 \\
\hline
\end{tabular}

O experimento teve duração de 167 dias - um período de adaptação de 55 dias e quatro períodos de 28 dias. Os animais foram pesados no início do experimento, após o período de adaptação, e posteriormente a cada 28 dias. Antes das pesagens, inicial e final, os animais foram submetidos a jejum de sólidos 
por 16 horas, porém as pesagens intermediárias foram feitas sem jejum.

O delineamento experimental utilizado foi o de blocos casualizados, sendo a distribuição dos animais nos tratamentos com base no peso inicial, com quatro tratamentos e sete repetições, atendendo ao seguinte modelo estatístico:

$$
Y_{i k j l}=m+\tilde{n}_{i}+t_{j}+\tilde{n}_{i} x t_{j}+b_{k}+e_{i j k}
$$

em que: $Y_{i k j l}=$ observação dos tratamentos i j no bloco k; $\mathrm{m}=$ média geral; $\tilde{\mathrm{n}}_{\mathrm{i}}=$ efeito da fonte protéica $\mathrm{i}=(1,2)$; $\mathrm{t}_{\mathrm{j}}=$ efeito do aditivo $\mathrm{j}$, em que $\mathrm{j}=(1,2) ; \tilde{n}_{\mathrm{i}} \mathrm{x} \mathrm{t}_{\mathrm{j}}=$ efeito da interação de fonte protéica e aditivo na silagem; $\mathrm{b}_{\mathrm{k}}=$ efeito do bloco $\mathrm{k}$, em que $\mathrm{k}=(1, \ldots, 7) ; \mathrm{e}_{\mathrm{ijk}}=$ efeito do erro experimental relativo à observação.

Foram utilizados quatro tratamentos com sete animais cada.

$\mathrm{T}_{1}$ : Silagem de capim-elefante com acipin + ração concentrada com uréia

$\mathrm{T}_{2}$ : Silagem de capim-elefante com acipin + ração concentrada com farelo de soja

$\mathrm{T}_{3}$ : Silagem de capim-elefante sem acipin + ração

T4: silagem de capim-elefante sem acipin e concentrado com farelo de soja).

Os resultados foram interpretados por meio de análise de variância, pelo teste Tukey (5\% de probabilidade).

A ração fornecida e as sobras foram pesadas diariamente para cada tratamento e animal. Amostras de ração e de sobras foram coletadas todos os dias, armazenadas em sacos plásticos devidamente identificados e congeladas a $-10^{\circ} \mathrm{C}$. Posteriormente, foram homogeneizadas e agrupadas para que fossem formadas amostras compostas semanais. Em seguida, as amostras foram submetidas à pré-secagem em estufa de circulação forçada de $55^{\circ} \mathrm{C}$ a $60^{\circ} \mathrm{C}$, por 72 horas. Depois de pré-secas, foram submetidas ao processo de moagem em moinho tipo "Willey" com peneira de 30 "Mesh". Após este procedimento, estas amostras foram homogeneizadas e agrupadas novamente para a formação de amostras compostas por período por animal, para a realização das análises. As determinações de matéria seca (MS), fibra em detergente neutro (FDN), proteína bruta (PB), extrato etéreo (EE), cálcio (Ca) e fósforo (P) foram feitas de acordo com as metodologias descritas por Silva (1990).
As silagens de capim-elefante, com e sem aditivo (acipin), utilizadas no confinamento foram submetidas ao ensaio de digestibilidade com quatro ovinos, machos, castrados, previamente vacinados e desverminados. Os animais foram mantidos individualmente em gaiolas de estudos metabólicos, com água e sal mineral à vontade. As fezes foram coletadas por meio de bolsas (coletoras) colocadas três dias antes do período de coleta para adaptação dos animais.

A digestibilidade foi calculada pela seguinte fórmula:

$$
\frac{\mathrm{kg} \text { MS fornecida }-\mathrm{kg} \text { MS rejeitada }-\mathrm{kg} \text { MS excretada }}{\text { nas fezes }} \times 1
$$

O ensaio de digestibilidade constou de duas fases distintas: na primeira, os animais passaram por um período de adaptação de 15 dias, quando receberam silagem à vontade. Na segunda fase, iniciou o período de coleta, com duração de seis dias.

A silagem foi fornecida duas vezes ao dia, pela manhã (8 h) e à tarde (16 h). A silagem fornecida foi pesada e amostrada, assim como as sobras e as fezes. As amostras foram colocadas em sacos plásticos, devidamente fechados, etiquetados e armazenados em congelador, a $-10^{\circ} \mathrm{C}$, até o processamento das mesmas. Ao final de cada período de coleta, foram descongeladas, homogeneizadas para formação de amostras compostas semanais por animal e pré-secas, para análises posteriores de matéria seca, conforme procedimentos descritos anteriormente.

Os ovinos foram distribuídos aleatoriamente recebendo, por sorteio, uma das seqüências dos tratamentos, em três períodos experimentais sucessivos, seguindo o esquema indicado na Tabela 4.

O delineamento foi inteiramente casualizado, com duas repetições, em um arranjo fatorial com dois tipos de silagem e três períodos, conforme modelo a seguir:

$$
Y_{i j}=m+t_{i}+\tilde{n}_{k}+t_{i} x \tilde{n}_{k}+e_{i j k} \text {, }
$$

em que $\mathrm{Y}_{\mathrm{ij}}=$ observação relativa ao tratamento $\mathrm{i}$, repetição $j ; m$ = média geral; $t_{i}=$ efeito do tipo de silagem $\mathrm{i}$; $\tilde{\mathrm{n}}_{\mathrm{k}}=$ efeito do período $\mathrm{k}$; $\mathrm{t}_{\mathrm{i}} \mathrm{x} \tilde{\mathrm{n}}_{\mathrm{k}}=$ efeito da interação de tipo de silagem i e período $\mathrm{k} ; \mathrm{e}_{\mathrm{ijk}}=$ efeito do erro experimental aleatório. 
Tabela 4 - Seqüência de tratamentos para ensaio de digestibilidade aparente da matéria seca Table 4 - Sequence of treatments for the apparent dry matter digestibility trial

\begin{tabular}{|c|c|c|c|c|}
\hline \multirow[b]{2}{*}{$\begin{array}{l}\text { Períodos } \\
\text { Periods }\end{array}$} & \multicolumn{4}{|c|}{$\begin{array}{c}\text { Ovinos (seqüências) } \\
\text { Sheep (sequences) }\end{array}$} \\
\hline & 1 & 2 & 3 & 4 \\
\hline I & $\begin{array}{l}\text { Silagem c/acipin } \\
\text { Silage w/acipin }\end{array}$ & $\begin{array}{l}\text { Silagem s/acipin } \\
\text { Silage wt/acipin }\end{array}$ & $\begin{array}{l}\text { Silagem c/ acipin } \\
\text { Silage w/acipin }\end{array}$ & $\begin{array}{l}\text { Silagem s/ acipin } \\
\text { Silage wt/acipin }\end{array}$ \\
\hline II & $\begin{array}{l}\text { Silagem s/ acipin } \\
\text { Silage wt/acipin }\end{array}$ & $\begin{array}{l}\text { Silagem c/acipin } \\
\text { Silage w/acipin }\end{array}$ & $\begin{array}{l}\text { Silagem s/acipin } \\
\text { Silage wt/acipin }\end{array}$ & $\begin{array}{l}\text { Silagem c/ acipin } \\
\text { Silage w/acipin }\end{array}$ \\
\hline III & $\begin{array}{l}\text { Silagem c/acipin } \\
\text { Silage w/acipin }\end{array}$ & $\begin{array}{l}\text { Silagem s/acipin } \\
\text { Silage wt/acipin }\end{array}$ & $\begin{array}{l}\text { Silagem c/acipin } \\
\text { Silage w/acipin }\end{array}$ & $\begin{array}{l}\text { Silagem s/ acipin } \\
\text { Silage wt/acipin }\end{array}$ \\
\hline
\end{tabular}

\section{Resultados e Discussão}

O teor médio de matéria seca da silagem de capim-elefante com acipin foi de 27,65\% (Tabela 3), valor semelhante $(\mathrm{P}>0,05)$ ao obtido com a silagem sem aditivo (26,38\%) e abaixo dos $30 \%$ sugeridos por Gordon et al. (1967) e Tosi (1973), para ensilagem de gramíneas tropicais.

A silagem com acipin apresentou maior $(9,81 \%)$ teor médio de proteína bruta que a silagem sem acipin $(6,14 \% ; \mathrm{P}<0,05)$ (Tabela 3). Estes dados evidenciam a contribuição do acipin para o aumento dos teores de PB da silagem. De acordo com Thomas (1982), maior porcentagem de ácido lático na silagem, como é o caso da silagem com acipin, ajuda a evitar maiores perdas por degradação proteolítica. Portanto, infere-se que os resultados de maior porcentagem de PB da silagem com acipin sejam, em parte, conseqüência de menores perdas em comparação à silagem sem acipin, evidenciando a contribuição do acipin na melhoria da fermentação da silagem de capim-elefante.

A silagem com acipin apresentou teor médio de fibra em detergente neutro menor $(\mathrm{P}<0,05)$ que a silagem sem acipin, 71,28 e 77,84\%, respectivamente, possivelmente em decorrência de um processo de diluição, quando se adicionou o aditivo ao material a ser ensilado, posto que o aditivo não contém fibra.

Observam-se diferenças $(\mathrm{P}<0,05)$ entre os teores de extrato etéreo para silagem com e sem acipin, 2,13 e $1,71 \%$, respectivamente. A diferença entre os teores médios EE pode ser atribuída ao fato de que parte dos ácidos orgânicos, como polímeros de ácido lático contido no aditivo, possivelmente foi extraída durante o procedimento da análise.

R. Bras. Zootec., v.33, n.6, p.2095-2103, 2004 (Supl. 2)
Teores de cálcio e de fósforo não apresentaram grande alteração entre as silagens com e sem acipin, 0,022 e 0,027 para cálcio e 0,008 e 0,012 para fósforo, respectivamente. Portanto, pode-se inferir que a adição do acipin à silagem não influi na concentração desses macroelementos.

Os pesos médios, iniciais e finais, ganhos médios diários, consumo de matéria seca e conversão alimentar encontram-se na Tabela 5.

O consumo de matéria seca foi baixo e, conseqüentemente, o ganho médio diário de peso e o peso final dos animais. Mesmo após 167 dias de confinamento, incluindo o período de adaptação, os animais não atingiram o peso de abate, apesar de estarem recebendo diariamente $4 \mathrm{~kg}$ de ração concentrada por animal. Além disso, silagens de capins, normalmente, apresentam baixo consumo, o que também foi observado no presente trabalho.

Embora não tenha havido diferença estatística $(\mathrm{P}>0,05)$ entre tratamentos para ganho de peso, os tratamentos com farelo de soja T2 $(0,593)$ e T4 $(0,648)$ foram os que apresentaram numericamente melhores resultados. Comparando estes resultados com os encontrados por Henrique et al. (1993), $1,03 \mathrm{~kg} /$ dia, utilizando silagem de capim-elefante com $20,36 \%$ de MS + concentrado com $17,67 \%$ de PB, e por Boin (1975), 1,029 kg/dia, que trabalharam com silagem de capim-elefante com 77 dias, suplementada com $0,5 \mathrm{~kg}$ de farelo de algodão + $3 \mathrm{~kg}$ de concentrado com $21 \%$ $\mathrm{PB}$, observa-se que estes foram bem inferiores. No entanto, este valor encontra-se bastante próximo ao obtido por Gomide \& Paula (1973), de 0,635 kg/dia, usando silagem de capim-elefante com 210 dias + suplementação com 4,5 kg de MDPS + 0,7 de farelo de soja. 
A adição de acipin à silagem não influenciou o ganho de peso final dos animais, observando-se o mesmo com relação aos resultados obtidos para consumo de matéria seca e conversão alimentar, que não variaram entre os tratamentos.

Os consumos médios de MS por período e tratamento e o consumo médio total por tratamento são apresentados na Tabela 6.

Os consumos médios observados apresentaram comportamento bastante variado em relação aos tratamentos, assim como ao longo do período de confinamento. Os consumos registrados são relativamente baixos, uma vez que, em média, apenas 6,65 kg/dia de MS foram consumidos. Verifica-se que os valores médios de cada tratamento apresentam-se muito próximos. Embora a silagem de capim- elefante com acipin tenha apresentado melhores teores de nutrientes, as diferenças no consumo médio de MS não foram observadas $(\mathrm{P}>0,05)$. Estes resultados poderiam ser atribuídos ao alto teor de concentrado ( $\pm 60 \%$ da ração total, na MS) fornecido na dieta total dos animais, confundindo-se, desta forma, o grau de aceitabilidade de ambas as silagens pelos animais, pois o concentrado era misturado ao volumoso.

Comparando-se as fontes protéicas utilizadas, observa-se que as médias do consumo de MS expressas em $\mathrm{kg} /$ dia foram numericamente superiores quando se utilizou farelo de soja no concentrado (T2 e T4).

Ao considerar os resultados de ganho observado, comparando os consumos obtidos e esperados (Tabela 7), nota-se que o ganho de peso médio foi abaixo do esperado, o que se deve, em parte, ao

Tabela 5 - Pesos médios iniciais e finais, em kg; ganhos médios diários e consumo de MS, em kg/animal/dia; e conversão alimentar, em $\mathrm{kg}$ de $\mathrm{MS} / \mathrm{kg}$ de ganho de peso vivo

Table 5 - Average initial and final live weights, in kg; daily weight gains and dry matter intake, in $\mathrm{kg} / \mathrm{animal} / \mathrm{day}$; and feed conversion, in $\mathrm{kg}$ of $\mathrm{DM} / \mathrm{kg}$ of live weight gain

Peso inicial (kg) (Initial live weight, $\mathrm{kg}$ )

Peso final (kg) (Final live weight, $\mathrm{kg}$ )

Ganho de peso diário (kg) (Daily weight gain, $\mathrm{kg}$ )

Consumo de MS (kg) (Dry matter intake, $\mathrm{kg}$ )

Conversão alimentar (Feed conversion)

\begin{tabular}{cccc} 
T1 & T2 & T3 & T4 \\
\hline 309,00 & 309,86 & 309,86 & 310,71 \\
370,86 & 376,29 & 367,57 & 383,29 \\
0,552 & 0,593 & 0,515 & 0,648 \\
6,38 & 6,83 & 6,59 & 6,78 \\
11,15 & 11,51 & 12,79 & 10,46 \\
\hline
\end{tabular}

$\mathrm{T}_{1}$ : Silagem de capim-elefante com acipin + ração concentrada com uréia.

$T_{1}$ : Elephantgrass silage with acipin + concentrate ration with urea.

$\mathrm{T}_{2}$ : Silagem de capim-elefante com acipin + ração concentrada com farelo de soja.

$T_{2}$ : Elephantgrass silage with acipin + concentrate ration with soybean meal.

$\mathrm{T}_{3}$ : Silagem de capim-elefante sem acipin + ração concentrada com uréia.

$T_{3}$ : Elephantgrass silage without acipin + concentrate ration with urea.

$\mathrm{T}_{4}$ : Silagem de capim-elefante sem acipin + ração concentrada com farelo de soja.

$T_{4}$ : Elephantgrass silage without acipin + concentrate ration with soybean meal.

Tabela 6 - Consumos médios diários em kg de MS por animal, por período e tratamento, e média dos quatro períodos em $\mathrm{kg}$ por animal e em porcentagem do peso vivo (\%PV)

Table 6 - Mean daily dry matter intake in $\mathrm{kg}$ by animal for each period and treatment, and the average for the four periods in $\mathrm{kg}$ by animal and in percentage of live weigh (\% LW)

\begin{tabular}{|c|c|c|c|c|c|c|}
\hline \multirow[b]{2}{*}{$\begin{array}{l}\text { Tratamentos } \\
\text { Treatments }\end{array}$} & \multicolumn{4}{|c|}{$\begin{array}{l}\mathrm{kg} / \mathrm{animal} / \mathrm{dia} \\
\mathrm{kg} / \text { animal/day }\end{array}$} & \multirow[b]{2}{*}{$\begin{array}{c}\text { Média } \\
\text { Mean }\end{array}$} & \multirow[b]{2}{*}{$\begin{array}{l}\% \mathrm{PV} \\
\% L W \\
\end{array}$} \\
\hline & $\begin{array}{c}1 \text { o período } \\
1^{\text {st }} \text { period }\end{array}$ & $\begin{array}{c}2 \underline{0} \text { período } \\
2^{\text {nd }} \text { period } \\
\end{array}$ & $\begin{array}{c}3^{o} \text { período } \\
3^{r d} \text { period }\end{array}$ & $\begin{array}{c}4^{\mathrm{o}} \text { período } \\
4^{\text {th }} \text { period }\end{array}$ & & \\
\hline $\mathrm{T} 1$ & 6,05 & 7,01 & 5,99 & 6,49 & 6,38 & 1,88 \\
\hline $\mathrm{T} 2$ & 6,53 & 7,14 & 6,75 & 6,91 & 6,83 & 1,99 \\
\hline T3 & 6,49 & 6,69 & 7,28 & 5,94 & 6,60 & 1,95 \\
\hline T4 & 6,36 & 6,52 & 7,62 & 6,63 & 6,78 & 1,96 \\
\hline
\end{tabular}

\footnotetext{
R. Bras. Zootec., v.33, n.6, p.2095-2103, 2004 (Supl. 2)
} 
Tabela 7 - Ganho de peso médio diário em kg, por tratamento, observado e esperado segundo o NRC (1996), considerando o consumo de MS e a composição das rações

Table 7 - Mean live weights gains in $\mathrm{kg}$, for each treatment, observed and estimated according to NRC (1996), considering the dry matter intake and the ration composition

\begin{tabular}{lcc}
\hline $\begin{array}{l}\text { Tratamento } \\
\text { Treatment }\end{array}$ & $\begin{array}{c}\text { Ganho observado } \\
\text { Observed gain }\end{array}$ & $\begin{array}{c}\text { Ganho esperado } \\
\text { (NRC, 1996) } \\
\text { Expected gain } \\
\text { (NRC, 1996) }\end{array}$ \\
\hline T1 & $0,552 \mathrm{a}$ & 0,840 \\
$\mathrm{~T} 2$ & $0,593 \mathrm{a}$ & 0,890 \\
$\mathrm{~T} 3$ & $0,515 \mathrm{a}$ & 0,860 \\
$\mathrm{~T} 4$ & $0,648 \mathrm{a}$ & 0,880 \\
\hline $\mathrm{a}-$ Valores seguidos de mesmas & letras não diferem \\
a - Valuesticamente $(\mathrm{P}>0,05)$. &
\end{tabular}

consumo de MS inferior ao necessário para alcançar o ganho desejado proposto pelo NRC (1996).

A partir dos resultados obtidos pelas análises de variância (Tabela 8) para ganho de peso, constata-se que não houve diferença significativa $(\mathrm{P}>0,05)$ entre silagem de capim-elefante com e sem acipin. O mesmo foi observado entre as fontes protéicas, uréia e farelo de soja. No entanto, ao se avaliarem os valores médios (Tabela 5), verifica-se que os animais alimentados com farelo de soja no concentrado (T2 e T4) obtiveram numericamente ganho de peso diário superior àqueles que receberam uréia (T1 e T3). Segundo Clifford \& Tillman (1968) e Campos \& Rodrigues
(1984), a uréia não é tão eficiente quanto o farelo de soja em promover bom desempenho animal. De acordo com Bloomfield et al. (1960) e Chalupa (1972), citados por Rihani et al. (1993), parte da ineficiência de utilização do nitrogênio não-protéico (NNP) tem sido atribuída ao excesso de produção de amônia no rúmen, que é absorvida, convertida em uréia, e excretada na urina.

Obeid et al. (1980), substituindo parcialmente e totalmente o farelo de soja pela uréia, em ração para bovinos, obtiveram, respectivamente, ganhos de 0,960 e $0,770 \mathrm{~kg} /$ dia para os concentrados fornecidos em mistura junto com a silagem de milho. Este resultado deve-se, provavelmente, à fonte de proteína, pois, em razão de o farelo de soja ser de degradabilidade mais lenta, houve aumento da atividade microbiana, melhorando a fermentação e a taxa de passagem, elevando a digestibilidade e, conseqüentemente, o consumo alimentar. Segundo Paterson et al. (1994), citados por Haddad \& Castro (1988), a suplementação protéica é recomendada para o melhor aproveitamento, com o aumento da utilização das forragens.

Os coeficientes de digestibilidade aparente da MS da silagem de capim-elefante com e sem acipin constam na Tabela 9. A análise de variância não mostrou diferença estatisticamente significativa $(\mathrm{P}>0,05)$ entre a silagem de capim-elefante com e sem acipin. Neste caso, infere-se que este aditivo, no teor utilizado, não foi eficiente em melhorar o coeficiente de digestibilidade da silagem de capim-elefante.

Tabela 8 - Análise de variância dos ganhos de peso e coeficiente de variação Table 8 - Variance analysis of the weight gains and the coefficient of variation

\begin{tabular}{|c|c|c|c|c|c|}
\hline $\begin{array}{l}\text { Fontes de variação } \\
\text { Sources of variation }\end{array}$ & GL & SQ & QM & $\mathrm{F}$ & SIG \\
\hline $\begin{array}{l}\text { Bloco } \\
\text { Block }\end{array}$ & 6 & 0,06532434 & 0,01088739 & & $0,65 \quad \mathrm{NS}$ \\
\hline $\begin{array}{l}\text { Fonte protéica (FP) } \\
\text { Protein source (PS) }\end{array}$ & 1 & 0,05266034 & 0,05266034 & 3,15 & NS \\
\hline $\begin{array}{l}\text { Acipin } \\
\text { Acipin }\end{array}$ & 1 & 0,00055802 & 0,00055802 & 0,03 & NS \\
\hline $\begin{array}{l}\mathrm{FP}^{*} \text { aditivo } \\
P S^{*} \text { Acipin }\end{array}$ & 1 & 0,01475946 & 0,01475946 & 0,88 & NS \\
\hline $\begin{array}{l}\text { Erro } \\
\text { Error }\end{array}$ & 18 & 0,3012026 & 0,01673348 & & \\
\hline
\end{tabular}

Coeficiente de variação $=22,41 \%$ (Coefficient of variation $=22.41 \%$ ).

NS - Não-significativo (NS - Not significant). 
Tabela 9 - Digestibilidade aparente da matéria seca da silagem de capim-elefante com e sem acipin Table 9 - Apparent dry matter digestibility of elephantgrass silage with and without acipin

\begin{tabular}{|c|c|c|c|c|c|}
\hline Tratamentos & & Período & & Média & $\mathrm{CV}$ \\
\hline Treatments & & Periods & & Mean & $\%$ \\
\hline & I & II & III & & \\
\hline $\begin{array}{l}\text { Silagem com acipin } \\
\text { Silage with acipin }\end{array}$ & $55,45 a$ & $56,26 a$ & 39,83a & 50,51 & 21,08 \\
\hline $\begin{array}{l}\text { Silagem sem acipin } \\
\text { Silage without acipin }\end{array}$ & $59,14 a$ & $59,47 a$ & $38,17 a$ & 52,26 & \\
\hline
\end{tabular}

Os valores obtidos de coeficiente de digestibilidade aparente corroboram os resultados observados na literatura. Silveira et al. (1973) obtiveram coeficiente de 49,2\%, para silagem de capim-elefante sem aditivo cortada aos 86 dias, enquanto Evangelista et al. (1988), de 49,0\%, para silagem de capim-elefante cortada aos 90 dias.

\section{Conclusões}

A adição do acipin à silagem de capim-elefante não proporcionou melhor desempenho quando comparado à silagem sem o aditivo. Farelo de soja e uréia, utilizados nos concentrados, não apresentaram diferença em relação ao desempenho dos animais. $\mathrm{O}$ aditivo não resultou em diferenças significativas no coeficiente de digestibilidade da matéria seca. Embora o aditivo não tenha influenciado diretamente o desempenho dos animais, observou-se aumento no teor de proteína bruta da silagem. Portanto, para recomendar o aditivo, mais estudos devem ser realizados com diferentes níveis de aditivo no preparo da silagem.

\section{Literatura Citada}

BOIN, C. Elephantgrass silage production effect of additives on chemical composition nutritive value and animal performance. Cornell: Cornell University: 1975. 215p. PhD Thesis - Cornell University, 1975.

CAMPOS, O.F.; RODRIGUES, A.A. Uréia para bovinos em crescimento. In: SIMPÓSIO SOBRE NUTRIÇÃO DE BOVINOS - URÉIA PARA RUMINANTES, 1984, Piracicaba. Anais... Piracicaba: Fundação de Estudos Agrários Luiz de Queiroz, 1984. p.142-173.

CLIFFORD, A.J.; TILLMAN, A.D. Urea and isolated soybean protein in sheep purified diets. Journal of Animal Science, v.27, n.2, p.484-489, 1968.

DEN UIJL, C.H.; Van BURIK, A.M.C. The preserving effect of lactic acid and lactates. International Food Ingredients, v.2, p.34-38, 1990.
EVANGELISTA, A.R.; TEIXEIRA, J.C.; REZENDE, P.M. et al. Níveis de associação de soja (Glycine Max, Merrill) com milho para ensilar: valor nutritivo. In: REUNIÃO ANUAL DA SOCIEDADE BRASILEIRA DE ZOOTECNIA, 21., 1988, Viçosa, MG. Anais ... Viçosa, MG: Sociedade Brasileira de Zootecnia, 1988. p.192.

GOMIDE, J.A.; PAULA, R.R. Silagem de capim-elefante e feno de leguminosas como fonte de energia e proteína para novilhos zebus em confinamento. Revista Ceres, v.20, n.108, p.110-119, 1973.

GORDON, C.H.; DERBYSHIRE, J.C.; NENEAR, J.R. Conservation and feeding value of low moisture orchardgrass stored in gas-tight and bunker silos. Journal of Dairy Science, v.50, n.7, p.1109-1115, 1967.

HADDAD, C.M.; CASTRO, F.G.F. Suplementação mineral em novilhos precoce - Uso de sais proteinados e energéticos na alimentação. In: SIMPÓSIO SOBRE PRODUÇÃO INTENSIVA DE GADO DE LEITE, 1988, Campinas. Anais..... Campinas: 1988. p.188-232.

HENRIQUE, W.; LEME, P.R.; JUSTO, C.L. et al. Uso da silagem de milho ou de capim-elefante e da sacharina na engorda de bovinos em confinamento. Boletim da Indústria Animal, v.50, n.1, p.61-67, 1993.

LAVEZZO, W.; LAVEZZO, O.E.N.M.; SILVEIRA, A.C. Efeitos do emurchecimento, formol e ácido fórmico sobre o consumo e digestibilidade de silagens de capim-elefante (Pennisetum purpureum, Schum). Revista da Sociedade Brasileira de Zootecnia, v.13, n.4, p.501-508, 1984.

MARTIN, L.C.T. Bovinos - volumosos suplementares. São Paulo: Nobel, 1997. 143p.

McCUlLOUGH, M.E. Silage and silage fermentation. Feedstuffs, v.49, n.13, p.49-52, 1997.

NATIONAL RESEARCH COUNCIL - NRC. Nutrient requirements of beef cattle. 7.ed. Washington, D.C.: National Academy Science, 1996. 242p.

OBEID, J.A.; GOMIDE J.A.; COELHO DA SILVA, J.F. Efeito de níveis de uréia e do manejo da alimentação sobre o consumo alimentar e o ganho de peso de novilhos zebu em confinamento. Revistada Sociedade Brasileira de Zootecnia, v.9, n.3, p.484-493, 1980.

OMETTO, J.C. Bioclimatologia vegetal. São Paulo: Agronômica Ceres, 1981. 440p.

PURAC. Circular técnica. Campos dos Goytacazes, 1998. $56 \mathrm{p}$.

RIHANI, N.; GARRETT, W.N.; ZINN, R.A. influence of level of urea and method of supplementation on characteristics of 
digestion of high-fiber diets by sheep. Journal of Animal Science, v.17, n.6, p.1657-1665, 1993.

SILVA, D.J. Análise de alimentos (métodos químicos e biológicos). Viçosa, MG: Universidade Federal de Viçosa, 1990. 160p.

SILVEIRA, A.C.; FARIA, V.P.; TOSI, H. Efeito da maturidade sobre o valor nutritivo do capim napier. O solo, v.65, n.2, p.35-41, 1973.

TCACENCO, F.A. Seleção de caractéres para a classificação de três cultivares de capim-elefante. Pasturas Tropicales, v.10, n.1, p.14-19, 1988.

TCACENCO, F.A.; BOTREL, M.A. Identificação e avaliação de acessos e cultivares de capim-elefante. In: SIMPÓSIO SOBRE CAPIM-ELEFANTE, 1., 1990, Juiz de Fora. Anais... Coronel Pacheco: Embrapa Gado de Leite, 1990. p.1-22.

THOMAS, J.W. Curso Internacional sobre avaliação de forragens para ruminantes. Piracicaba: Fundação de Estudos Agrários Luiz de Queiroz, 1982 (Paginação irregular).
TOSI, H. Ensilagem de gramíneas tropicais sob diferentes tratamentos. Botucatu: Universidade Estadual de São Paulo, 1973. 107p. Tese (Doutorado) - Universidade Estadual de São Paulo, 1973.

XAVIER, D.F.; BOTREL, M.A.; DAHER, R.F. et al. Caracterização morfológica e agronômica de alguns cultivares de capim-elefante. Coronel Pacheco: Embrapa Gado de Leite, 1995. 24p. (Documentos, 60)

Recebido em: 22/08/02

Aceito em: 23/03/04 